\title{
Atypical nighttime spread- $F$ structure observed near the southern crest of the ionospheric equatorial ionization anomaly
}

\author{
P. R. Fagundes, ${ }^{1}$ J. A. Bittencourt, ${ }^{2}$ A. J. de Abreu, ${ }^{1}$ L. P. Moor, ${ }^{1}$ M. T. A. H. Muella, ${ }^{1}$ \\ Y. Sahai, ${ }^{1}$ J. R. Abalde, ${ }^{1}$ M. Pezzopane, ${ }^{3}$ J. H. A. Sobral, ${ }^{2}$ M. A. Abdu, ${ }^{2}$ A. A. Pimenta, ${ }^{2}$ \\ and D. C. M. Amorim ${ }^{2}$
}

Received 29 August 2011; revised 24 February 2012; accepted 27 February 2012; published 7 April 2012.

[1] An atypical nighttime spread- $F$ structure is observed on ionograms at or above the $F_{2}$ trace, near the crest of the ionospheric equatorial ionization anomaly (EIA) region. This ionospheric atypical spread- $F$ phenomenon was observed using two closed spaced $(\sim 115 \mathrm{~km})$ ionospheric soundings stations located in Sao Jose dos Campos $\left(23.21^{\circ} \mathrm{S}\right.$, $\left.45.97^{\circ} \mathrm{W}\right)$ and Cachoeira Paulista $\left(22.70^{\circ} \mathrm{S}, 45.01^{\circ} \mathrm{W}\right)$, Brazil, in a low-latitude station (near the southern crest of the EIA region), during nighttime, low solar activity, and quiet geomagnetic conditions. This structure, in the initial phase, appears in the ionogram as a faint spread- $F$ trace above or at the $F_{2}$-layer peak height. After a few minutes, it develops into a strong spread- $F$ trace, and afterwards, it moves to altitudes below the $F_{2}$-layer peak heights. Finally, the atypical nighttime $F$-layer trace structure may remain for a while between the $F$-layer bottom side and peak height or can move to an altitude above the $F$-layer peak height, and then it disappears. In order to have a comprehensive view of the ionospheric environment characterizing the phenomenon under study, complementary data from six GPS station were used to investigate the ionosphere environment conditions, during both events. The six GPS stations used in this study are distributed from near the equatorial region to low latitudes and provide evidence that the atypical nighttime spread- $F$ structures are not related with large scale equatorial irregularities (plasma bubbles).

Citation: Fagundes, P. R., et al. (2012), Atypical nighttime spread- $F$ structure observed near the southern crest of the ionospheric equatorial ionization anomaly, J. Geophys. Res., 117, A04308, doi:10.1029/2011JA017118.

\section{Introduction}

[2] Several $F$-layer phenomena at equatorial and low-latitude regions have attracted considerable interest of different investigating groups for over fifty years. Among these phenomena, spread- $F$, zonal electric field pre-reversal enhancement (PRE), equatorial ionospheric anomaly (EIA), and $F_{3}$-layer formation have been studied by numerous researchers. Nevertheless, these topics are still attracting much attention, particularly studies related to the day-to-day variability of these phenomena. In this paper, we report the occurrence of an atypical nighttime structure at or above the $F_{2}$-layer, near the southern crest of the EIA (low latitude).

[3] The ionospheric vertical electron density profile can be modified continuously by waves, chemistry, solar radiation, and solar activity. However, the main vertical features of the $D, E, F_{1}$, and $F_{2}$ layers are usually identifiable, except during strong geomagnetic storms. During daytime, the various

\footnotetext{
${ }^{1}$ Física e Astronomia, Universidade do Vale do Paraíba, Sao Jose dos Campos, Brazil.

${ }^{2}$ Instituto Nacional de Pesquisas Espaciais, Sao Jose dos Campos, Brazil.

${ }^{3}$ Istituto Nazionale di Geofisica e Vulcanologia, Rome, Italy.

ionospheric layers are normally present. During nighttime, the $D$ and $F_{1}$ layers disappear, while the $E$ layer takes some time to disappear, and finally, only the $F_{2}$-layer remains. Both theoretical and observational investigations, related to the day-to-day variability of the $F$-layer in equatorial and low-latitude regions, have become very active research subjects [Fagundes et al., 1999, 2009a, 2009b; Paul and DasGupta, 2010; Tsunoda, 2010]. The equatorial spread- $F$ (ESF) phenomenon is one of the most studied topics. The onset conditions and the possible causes for the day-to-day ESF variability are hot topics in this research area [Abdu et al., 1982a; Sastri et al., 1997]. Therefore, the knowledge related to ESF latitudinal and longitudinal morphology, seasonal and solar cycle variations for each longitudinal sector (American, Asian, and Indian), and zonal drift speeds has increased considerably during the last decade [Abalde et al., 2001; Bittencourt et al., 1997; Fagundes et al., 1995; Pimenta et al., 2001, 2003; Sahai et al., 2004, 2009; Sobral and Abdu, 1990; Sobral et al., 1999, 2011]. Calvert and Cohen [1961] investigated some characteristics of spread echoes, at equatorial region, on ionograms and conclude that its main feature depends on (a) nature of the scattering irregularities and (b) the distribution of them in the east-west plane with respect to the ionosonde. In fact, by taking into account appropriate distribution of scattering centers in the 


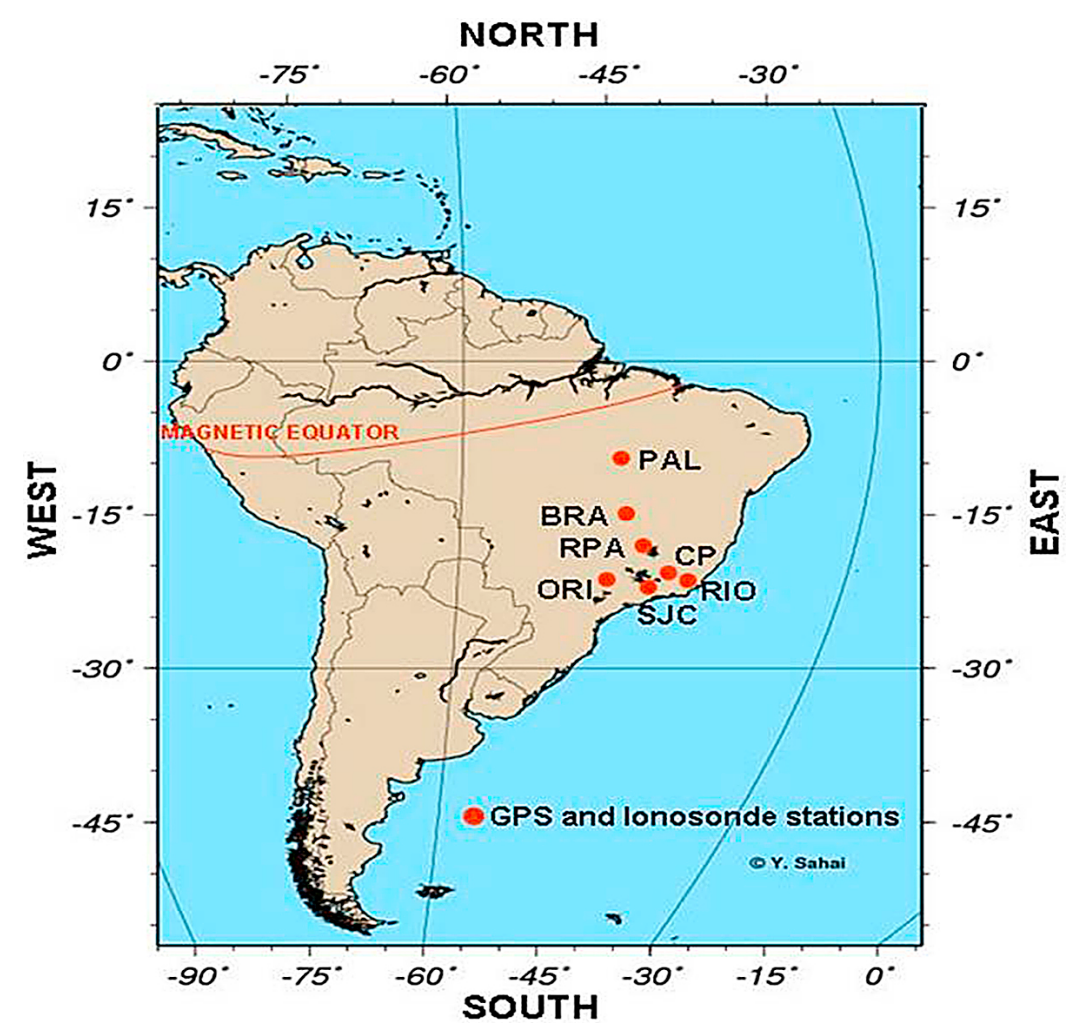

Figure 1. A map showing the locations of the digital ionosonde and GPS as well as stations used in the present study. In addition, the geographic and magnetic equators are shown.

east-west plane, they succeeded in simulating several features of the observed ESF signatures.

[4] $F_{3}$-layer formation and its day-to-day variability at equatorial and low latitudes is another topic that has become very active in the last decades. The $F_{3}$-layer is characterized by the formation of an additional electron density peak above the $F_{2}$-layer peak. Seasonal and solar cycle variations, possible sources, and occurrence during geomagnetically quiet and disturbed periods are the primary subjects explored related to the $F_{3}$-layer [Abdu et al., 1992; Balan and Bailey, 1995; Balan et al., 1997, 1998, 2008; Batista et al., 2002, 2003; Depuev and Pulinets, 2001; Jenkins et al., 1997; Lynn et al., 2000; Pulinets et al., 2002; Uemoto et al., 2006; Fagundes et al., 2007, 2011; Paznukhov et al., 2007; Rama Rao et al., 2005, Zain et al., 2008; Sreeja et al., 2009, 2010; Zhao et al., 2009; Klimenko et al., 2011]. Near the equatorial region, $F_{3}$-layer formation can be explained by the combined effects of a large $\mathbf{E} \times \mathbf{B}$ drift, during the morning period, which uplifts the $F_{2}$-layer around the magnetic equator, and a meridional wind flowing from the summer hemisphere to the winter hemisphere, which acts to raise the plasma in the summer hemisphere. However, the meridional wind near the magnetic equator has a smaller vertical component than at a few degrees of latitude away from the magnetic equator, and consequently, the $F_{3}$-layer is weaker at the magnetic equator and stronger a few degrees away from it [Jenkins et al., 1997]. Nevertheless, this mechanism based on the combined effects of $\mathbf{E} \times \mathbf{B}$ drift and meridional wind, proposed by Balan et al. [1997, 1998] for the equatorial region, does not explain $F_{3}$-layer formation near the southern crest of the equatorial ionospheric anomaly (EIA) in the American sector [Fagundes et al., 2007, 2011]. Therefore, based on observations, Fagundes et al. [2007] proposed that medium scale traveling ionospheric disturbances (MSTIDs), generated by gravity waves (GWs), can play an important role in $F_{3} / F_{2}$-layer stratification in the regions near the EIA crests.

[5] This paper presents and discusses two nighttime atypical spread- $F$ events similar to those observed by Calvert and Cohen [1961] at equatorial region, but the present observations were carried out in Sao Jose dos Campos $\left(23.21^{\circ} \mathrm{S}, 45.97^{\circ} \mathrm{W}\right)$ and in Cachoeira Paulista $\left(22.70^{\circ} \mathrm{S}, 45.01^{\circ} \mathrm{W}\right)$, Brazil, in a low-latitude station (near the southern crest of the ionospheric equatorial ionization anomaly - EIA). The most interesting feature of this atypical $F$-layer structure is their time evolution. In the initial phase, it appears as a weak spread- $F$ at or above the $F$-layer trace peak height. Afterwards, the spread- $F$ trace structure strengthens and moves to heights below the $F$-layer trace peak heights. Finally, this atypical structure shows electron density values larger than those of the $F$-layer and then disappears. In addition, GPS data of six stations were used to investigate the ionospheric environment along the meridional direction from near equatorial region to low latitude and over the two ionosonde stations. Figure 1 shows a map indicating the geographical position of the ionosondes and GPS stations used in this work.

\section{Observations and Results}

[6] Spread- $F$ at equatorial and low-latitudes regions is a well-known phenomenon and is closely related to largescale equatorial spread- $F$ (plasma bubbles), associated with 


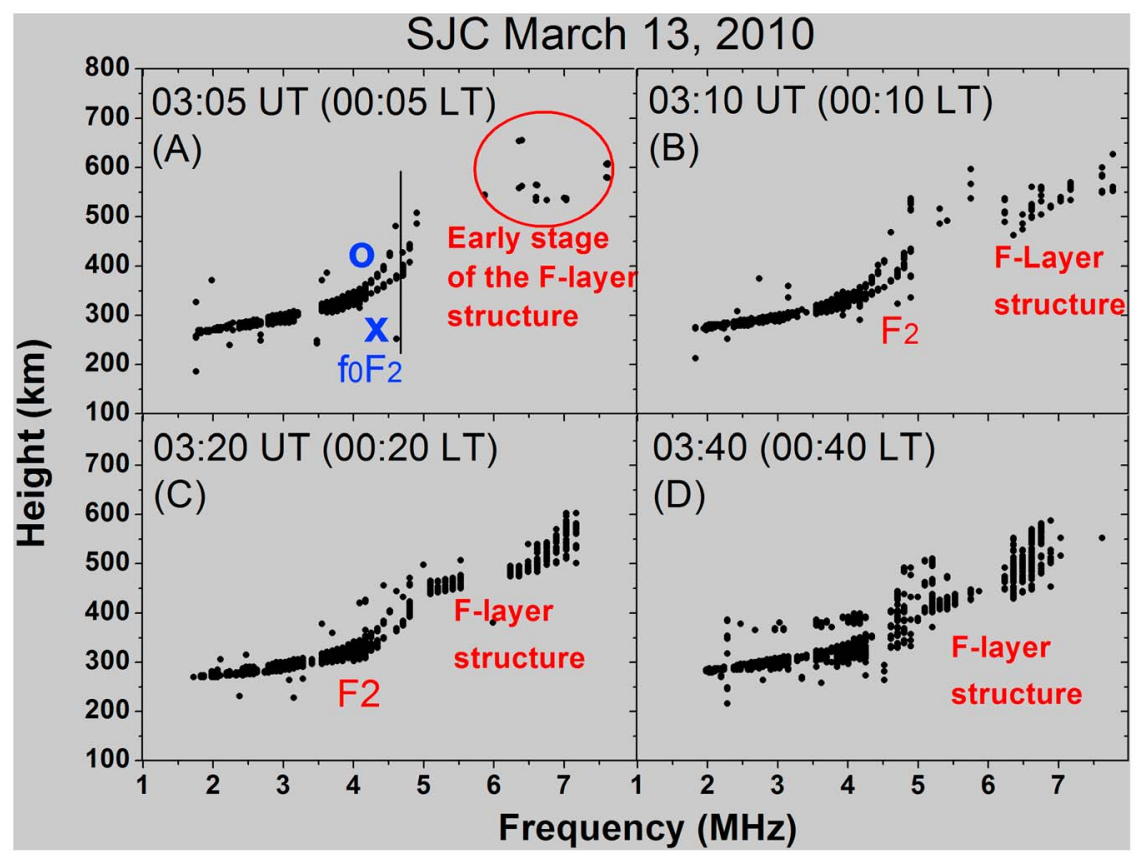

Figure 2. Ionograms obtained on March 13, 2010 in Sao Jose dos Campos. (a) The early stage of spread$\mathrm{F}$ trace structure formation; "O" and " $\mathrm{X}$ " indicate the ordinary and extraordinary traces; critical frequency $f_{o} F_{2}=4.6 \mathrm{MHz}$. (b) The spread- $F$ trace structure became stronger. (c) Spread- $F$ trace structure became a satellite trace to the $F_{2}$-layer traces. (d) The satellite traces (spread- $F$ traces structure) and the $F_{2}$-layer traces are much closer.

range spread- $F$ signatures on the ionograms [Fagundes et al., 1999; Abalde et al., 2001]. Also, in the equatorial and lowlatitudes regions a second class of spread- $F$ is observed, called frequency spread- $F$. Nevertheless, the observed spread- $F$ phenomenon described in this investigation seems to be unrelated to large-scale equatorial irregularities. This ionospheric atypical spread- $F$ phenomenon was observed from ionospheric soundings carried out in Sao Jose dos Campos $\left(23.21^{\circ} \mathrm{S}, 45.97^{\circ} \mathrm{W}\right.$; hereafter referred to as SJC) and Cachoeira Paulista $\left(22.70^{\circ} \mathrm{S}, 45.01^{\circ} \mathrm{W}\right.$; hereafter referred to as CP), Brazil, two closed-spaced low-latitude stations $(\sim 115 \mathrm{~km})$, near the southern crest of the EIA region, during nighttime, in geomagnetically quiet conditions, and low solar activity (Figures 2, 3, 4 and 5). These two closed spaced ionospheric stations (SJC and $\mathrm{CP}$ ) are separated by $\sim 0.5^{\circ}$ $(57 \mathrm{~km})$ in latitude and $\sim 1^{\circ}(99 \mathrm{~km})$ in longitude. Therefore, ionograms recorded almost simultaneously in these two stations, must have very similar traces. However, if small-scale irregularities propagate at ionospheric heights, in this region, then the ionogram traces observed in both sites will show differences. On the other hand, if large-scale ionospheric irregularities, with dimension of hundred kilometers, propagate over this region, it will be very difficult to notice any significant difference in the ionogram traces at both sites. Therefore, these two closed spaced ionosonde stations have a good configuration to study small-scale structures propagating around these sites.

[7] The six GPS data used in this work were obtained using the following receiving stations: Palmas (PAL), Brasilia (BRA), Rio Paranaiba (RPA), Rio de Janeiro (RIO), Ourinhos (OUR), and Sao Jose dos Campos (SJC). These GPS stations are located from near the magnetic equatorial to the crest of the
EIA region and over SJC and CP ionosonde stations. Figure 1 and Table 1 provide full details of the GPS receivers and the ionosonde stations considered in the present work. The GPS observations were used to obtain the rate of change of TEC, called ROT, this parameter is very useful to identify the presence of ionospheric irregularities [Aarons et al., 1997]. The presence or absence of large-scale irregularities, around a specific station, show very clear signature in the ROT signals (see Figure 6). On the contrary, the presence of small-scale irregularities is more difficult to observe by the change of TEC (ROT parameter).

[8] Figures 2, 3, 4, and 5 show step by step the development of the events observed on March 13, 2010 and March 19,2010 , in SJC and CP. Initially, the $F_{2}$-layer presents its usual behavior after a weak post-sunset uplift, if this is compared with those characterizing days of "fresh spread- $F$ " occurrence, which is probably associated with a small electric field pre-reversal enhancement (for more details about "fresh spread- $F$ " see Fagundes et al. [2009a, 2009b]. The ordinary and extraordinary traces are clear on the ionograms and the $f_{o} F_{2}$ critical frequency varies from 4 to $6 \mathrm{MHz}$. However, slightly above the $F_{2}$-layer peak height trace, a small spread- $F$ structure trace appears, with frequencies that are higher than the $F_{2}$-layer critical frequency $\left(f_{o} F_{2}\right)$. In the initial stage, this structure is faint and, not apparently related with the $F_{2}$-layer trace. However, after a few minutes, the structure trace becomes stronger and shows spread- $F$ characteristics. Then the structure trace moves to heights between the bottom side and the peak of the $F_{2}$-layer trace, and it turns into an atypical $F$-layer structure trace.

[9] The four phases characterizing the nighttime atypical spread- $F$ trace structure time evolution, that took place on 


\section{Cachoeira Paulista March 13, 2010}
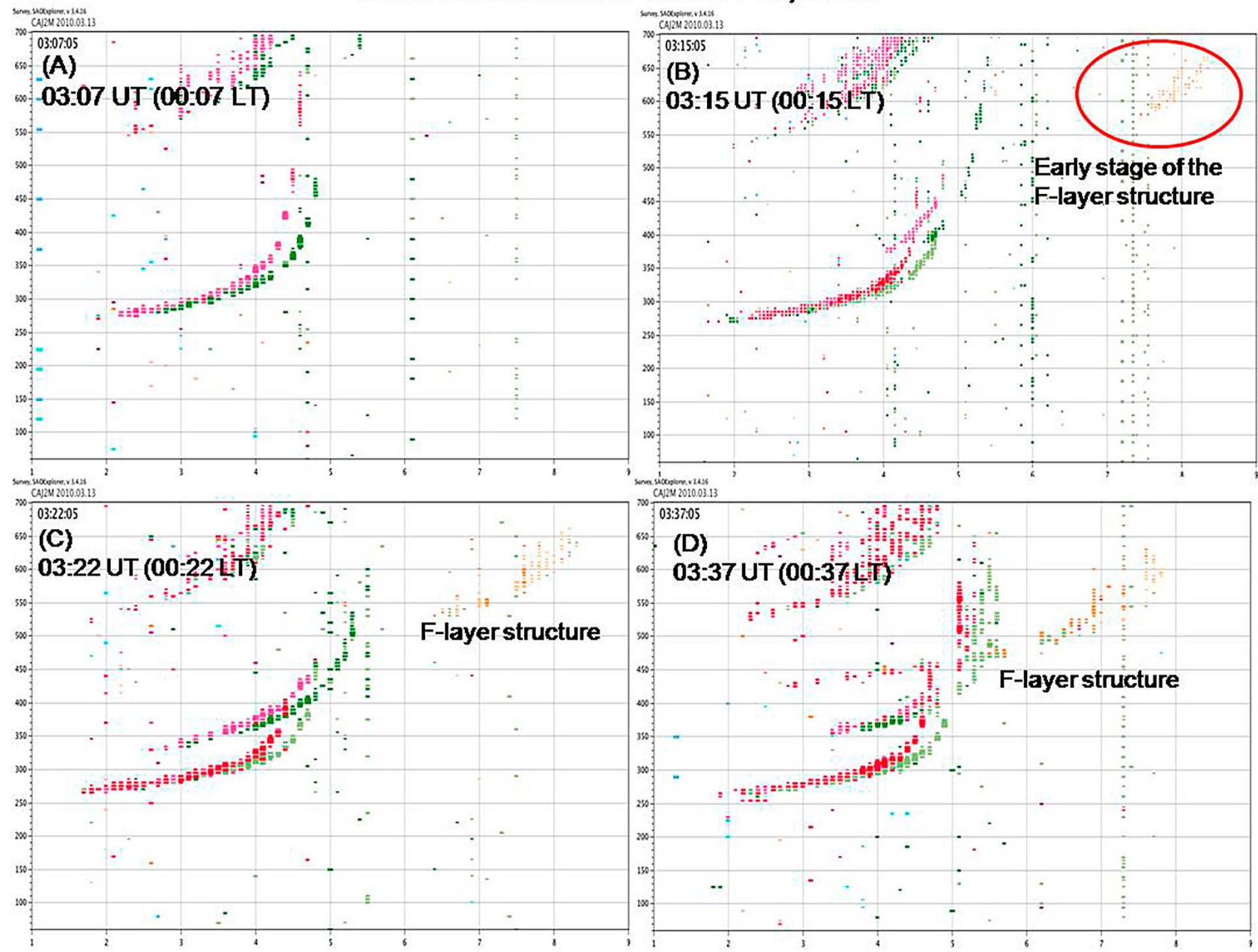

Figure 3. Ionograms obtained on March 13, 2010 in Cachoeira Paulista. (a) Ionogram just before the spread- $F$ trace structure appears. (b) The early stage of spread- $F$ trace structure formation. (c) The spread- $F$ traces structure becomes stronger. (d) Spread- $F$ trace structure became satellite traces of the $F_{2}$-layer.

March 13, 2010, are presented in Figures 2 and 3, for SJC and $\mathrm{CP}$, respectively. The observed atypical phenomenon is very dynamical and changes rapidly its characteristics in a time scale of a few minutes. Figure 2a shows an ionogram with the first stage of the nighttime atypical spread- $F$ trace structure in SJC at 03:05 UT (00:05 LT). The first echoes of this structure span between $530 \mathrm{~km}$ and $610 \mathrm{~km}$ in virtual height and range from 5.9 to $7.7 \mathrm{MHz}$. At this stage in SJC, it is not clear if these echoes belong to an atypical $F$-layer trace structure. The ionogram observed at 03:07 UT (00:07LT) in CP does not show any evidence of this atypical spread- $F$ trace structure, despite of the fact that these two sites are separated only $\sim 115 \mathrm{~km}$ (Figure $3 \mathrm{a}$ ). The first stage of the atypical spread- $F$ trace structure appears in $C P$ at 03:15 UT (00:15 LT, Figure 3b), indicating that the early stage of the spread- $F$ trace structure appears in $\mathrm{CP}$ only 10 min later than in SJC. On the other hand, at 03:10 UT $(00: 10 \mathrm{LT})$ in SJC (Figure 2b), the nighttime atypical spread$F$ trace structure becomes stronger and appears very clearly in the ionogram, with many more echoes. At this stage, the spread- $F$ trace structure is well-developed above or at the $F_{2}$-layer peak height, with frequencies higher than $f_{o} F_{2}$, and there is a gap between the $F_{2}$ critical frequency $\left(f_{o} F_{2}\right)$ and the range-type spread- $F$ trace structure minimum echo frequencies. Again, a few minutes later, the atypical spread- $F$ trace structure becomes stronger in CP (Figure 3c, 03:22 UT $(00: 22 \mathrm{LT}))$, but this ionogram shows both, a spread- $F$ structure and satellite traces. By then, the spread- $F$ trace structure has already became a satellite trace of the $F_{2}$-layer in SJC at 03:20 UT (00:20 LT, Figure 2c). The $F_{2}$-layer trace does not show spread- $F$ trace occurrence. On the other hand, the satellite trace (related to the spread- $F$ structure) changes from range to frequency spread- $F$ and presents a larger critical frequency than the $F_{2}$-layer. A similar ionogram is observed in CP at 03:37 UT (00:37 LT, Figure 3d). Finally, Figure $2 \mathrm{~d}$ (SJC) shows an ionogram recorded at 03:40 UT $(00: 40 \mathrm{LT}$ ), where the satellite traces (related to spread- $F$ trace structure) and the $F_{2}$-layer trace are seen to be much closer to each other. 


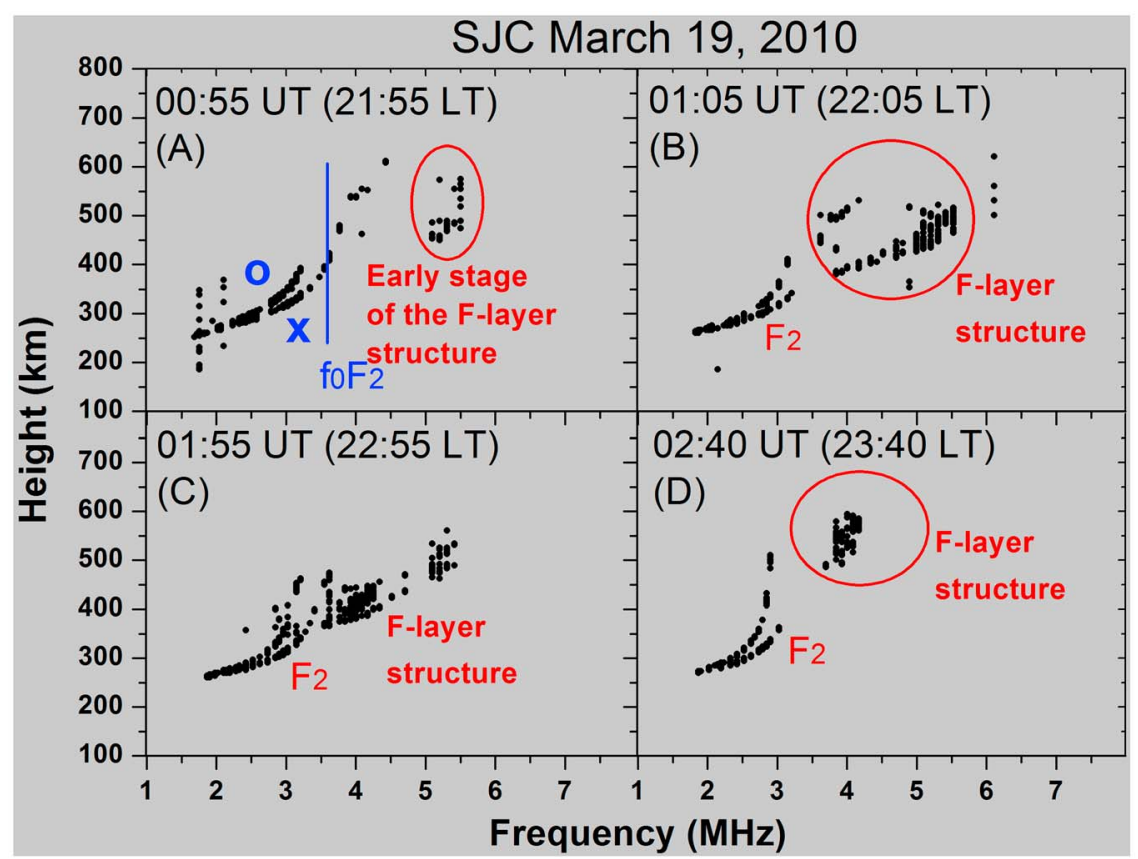

Figure 4. Ionograms obtained on March 19, 2010 in Sao Jose dos Campos. (a) The early stage of F3 spread- $F$ formation; "O" and " $\mathrm{X}$ " indicate the ordinary and extraordinary traces; critical frequency $f_{o} F_{2}=3.5 \mathrm{MHz}$. (b) The spread- $F$ traces became stronger. (c) The spread- $F$ trace structure became satellite traces of the $F_{2}$-layer traces. (d) The spread- $F$ trace gets higher altitudes.

[10] Figures 4 and 5 show four phases of another similar atypical spread- $F$ trace structure observed in SJC and $\mathrm{CP}$ on March 19, 2010. In the beginning of this event, the ordinary and extraordinary $F_{2}$-layer traces appear very clearly on the ionograms, in SJC at 00:55 UT (21:55 LT). Again, the initial phase of the atypical structure trace initiates with a few spread- $F$ echoes (Figure $4 a$ ), such as range spread- $F$ trace, but these echoes appear above or at the $F_{2}$-layer peak height trace and have frequencies between 5.0 to $5.5 \mathrm{MHz}$, which are higher than $f_{o} F_{2}(3.4 \mathrm{MHz})$. In this initial stage (00:55 UT 21:55 LT), it is not clear whether these echoes belong to an $F$-layer structure. It is important to note that also for this event the initial stage in CP appears 20 min later than in SJC, at 01:15 UT (22:15 LT) and remains until 01:22 (22:22 LT) (Figures 5a and 5b). A few minutes later in SJC (01:05 UT 22:05 LT), in the second phase, ordinary and extraordinary $F_{2}$-layer traces remain clear on the ionograms (Figure $4 \mathrm{~b}$ ), but the spread- $F$ trace structure is well developed. The spread- $F$ trace structure is well separated from the $F_{2}$-layer trace. The frequency gap between the $F_{2}$-layer critical frequency $\left(f_{o} F_{2}\right)$ and the first echoes of the spread- $F$ trace structure is also significant in this case. Figures $4 \mathrm{c}$ and $5 \mathrm{c}$ show the third phase of the event at 01:55 UT (22:55 LT) and 01:52 UT (22:52 LT) for SJC and CP, respectively. The ordinary and extraordinary traces of the $F_{2}$-layer are still clear, and only the atypical structure presents spread- $F$. However, this atypical spread- $F$ trace structure merges with the $F_{2}$-layer, close to the $F_{2}$ peak height. The last phase of the phenomenon under study is shown in Figures $4 \mathrm{~d}$ and $5 \mathrm{~d}$, in which the atypical spread- $F$ trace structure starts moving upward and appears much more separated from the $F_{2}$-layer trace. Finally, the structure disappears and the $F_{2}$-layer recovers its normal characteristics. A sequence of ionograms, as an animation, for SJC and CP can be seen in the auxiliary material, showing the time evolution of both events described in this paper. ${ }^{1}$ The time resolutions of ionograms are $5 \mathrm{~min}$ and $8 \mathrm{~min}$ for SJC and $\mathrm{CP}$, respectively.

[11] The rate of change of TEC (ROT) plots shown in Figure 6 for March 13 and 19, 2010 indicates that equatorial irregularities were generated during these nights, but were confined to equator and regions close by, as seen by the rapid and large ROT variations, recorded in PAL and BRA between 00:00 UT (21:00 LT) and 04:00 UT (01:00 LT) by most of the satellites (black rectangle in Figures 6a and 6b). The ROT recorded at RPA shows some evidence that the irregularities formed at equator reached latitudes between BRA and RPA on March 13, because, even though smaller, some satellites show ROT variation (green rectangle, in Figures $6 a$ and $6 b$ ). On the contrary, the ROT recorded in RIO for both days, does not show any signature of equatorial irregularities.

[12] Nevertheless, the presence of a small-scale structure was observed in ORI and SJC, on March 13 (Figure 6), at the same time that the atypical spread- $F$ structure under study was observed by ionosonde in SJC and CP. It is important to highlight that this structure must have been small, because only satellites 3 and 19 in ORI and satellite 19 in SJC detected the structure (red rectangle, Figures $6 \mathrm{a}$ and $6 \mathrm{~b}$ ).

[13] On the other hand, the atypical structure that was observed on March 19 by the ionosondes was probably even tinier, because the ROT recorded in ORI shows a very

\footnotetext{
${ }^{1}$ Auxiliary materials are available in the HTML. doi:10.1029/ 2011JA017118.
} 


\section{Cachoeira Paulista March 19, 2010}
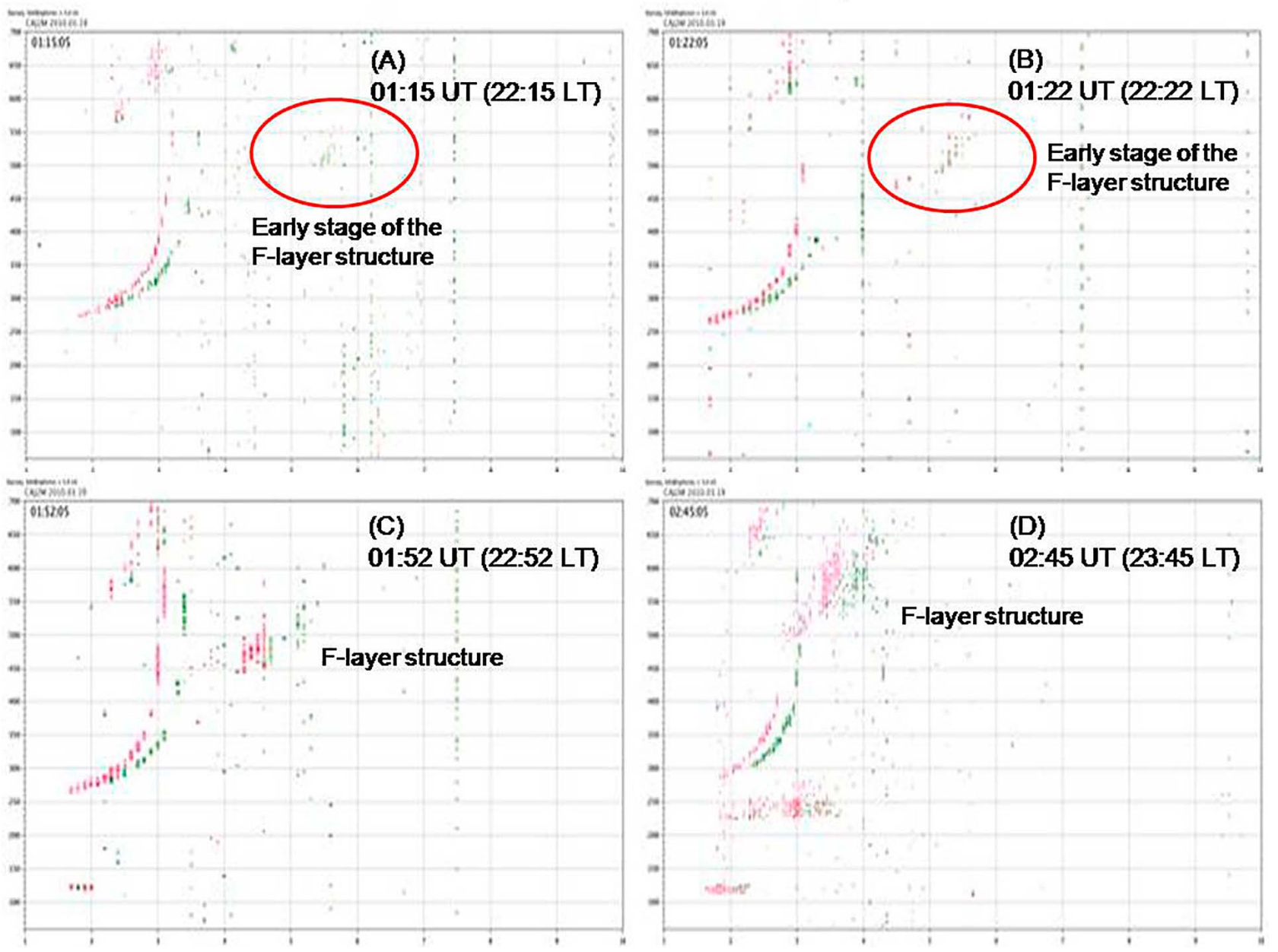

Figure 5. Ionograms obtained on March 19, 2010 in Cachoeira Paulista. (a) The early stage of spread- $F$ trace structure formation. (b) The early stage of spread- $F$ trace structure formation. (c) The spread- $F$ traces become stronger. (d) The spread- $F$ trace structure gets higher altitudes.

small and short change amplitude variation (red rectangle, Figure 6b). However, the ROT in RPA, RIO, and SJC did not show ROT variation.

\section{Discussion and Conclusions}

[14] Calvert and Cohen [1961] by observing atypical ionograms in Huancayo, at the magnetic equator, noticed atypical spread- $F$ trace signatures similar to those we illustrated in this paper. They mentioned that the observed irregularities were apparently anomalous and are more closely related to spread- $F$ observed at midlatitudes than the equatorial spread- $F$. Using the ray traced technique they concluded that the anomalous traces on the ionograms were generated by irregularities away from the overhead ionosonde site. However, their paper does not discuss the possible generation sources for this kind of structure. Unlike Calvert and Cohen [1961], the events described in this work were observed at low-latitudes, near the southern crest of the EIA.

[15] Recently, Lynn et al. [2011], using OI $630.0 \mathrm{~nm}$ emission all-sky imaging and ionospheric sounding simultaneous observations, showed evidence that ionograms that present satellite traces could be associated with large scale ionospheric irregularities (plasma bubbles). Their study observed the presence of satellite traces when the plasma bubble approached or move away from the ionospheric site and they interpreted these satellite traces as offangle echoes. However, the atypical spread- $F$ structure investigated in this paper, at low-latitudes, is not related to the equatorial large-scale irregularities (plasma bubble) coming from the equator, because the rate of change of TEC

Table 1. Details of the Digital Ionosondes and GPS Sites Used in the Present Study

\begin{tabular}{lccc}
\hline Location and Symbol & Instrument & Coordinates & Dip Latitude \\
\hline Palmas (PAL) & GPS & $10.2^{\circ} \mathrm{S}, 48.2^{\circ} \mathrm{W}$ & $05.7^{\circ} \mathrm{S}$ \\
Brasília (BRA) & GPS & $15.9^{\circ} \mathrm{S}, 47.9^{\circ} \mathrm{W}$ & $11.7^{\circ} \mathrm{S}$ \\
Rio Paranaíba (RPA) & GPS & $19.2^{\circ} \mathrm{S}, 46.1^{\circ} \mathrm{W}$ & $15.8^{\circ} \mathrm{S}$ \\
Cachoeira Paulista (CP) & DI & $22.7^{\circ} \mathrm{S}, 45.0^{\circ} \mathrm{W}$ & $19.2^{\circ} \mathrm{S}$ \\
Rio de Janeiro (RIO) & GPS & $22.8^{\circ} \mathrm{S}, 43.3^{\circ} \mathrm{W}$ & $19.8^{\circ} \mathrm{S}$ \\
Ourinhos (ORI) & GPS & $22.9^{\circ} \mathrm{S}, 49.9^{\circ} \mathrm{W}$ & $16.7^{\circ} \mathrm{S}$ \\
S. J. dos Campos (SJC) & DI and GPS & $23.2^{\circ} \mathrm{S}, 46.0^{\circ} \mathrm{W}$ & $17.6^{\circ} \mathrm{S}$ \\
\hline
\end{tabular}


(A)

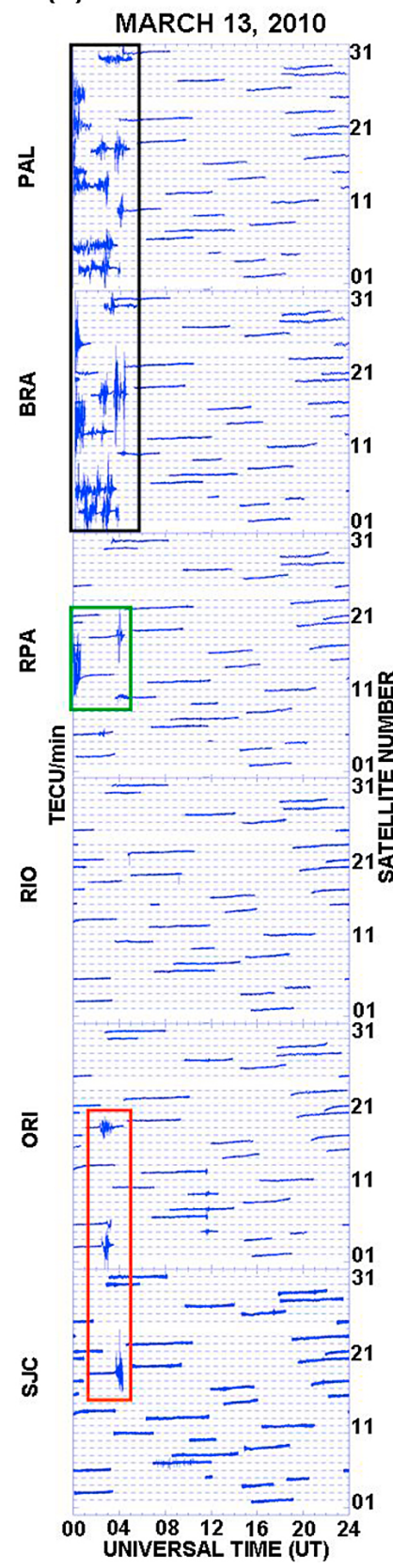

(B)

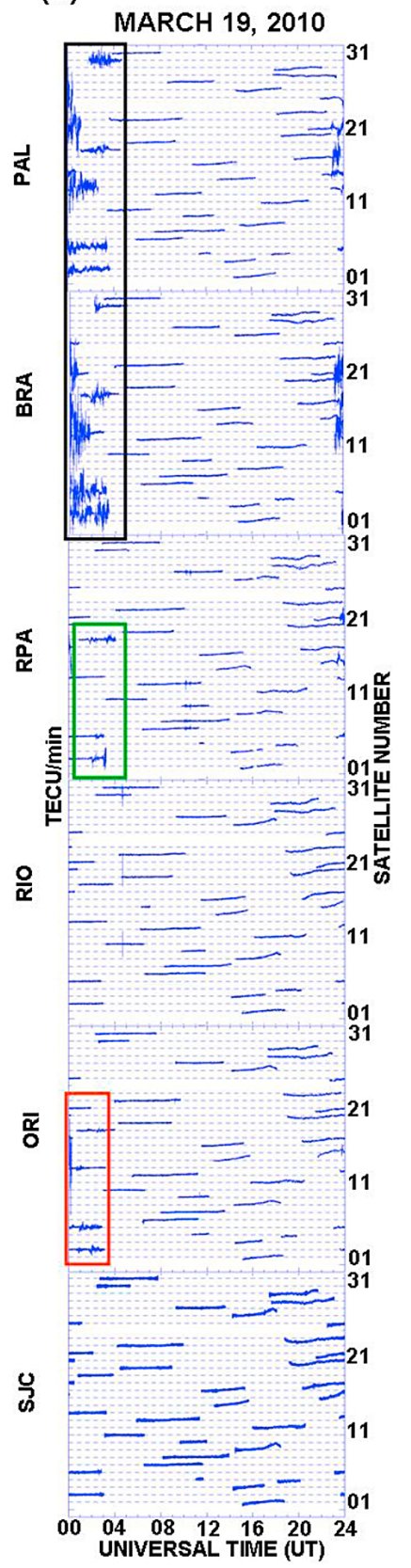

signatures indicate the presence of propagation of MSTIDs at low-latitude.

[16] In fact, propagation of GWs and MSTIDs has been suggested as a possible source of $F_{2}$-layer stratification and spread- $F$ signatures at low-latitudes in the Brazilian sector. $A b d u$ et al. [1982b] proposed that stratification of the nighttime $F_{2}$-layer, during the pre-sunrise period over $\mathrm{CP}$, is due to the passage of GWs. Pimenta et al. [2008], using a ground-based all-sky imaging system in $\mathrm{CP}$, observed dark band structures (MSTIDs) propagating from southeast to northwest. These optical measurements showed that the MSTIDs move quasi-horizontally through the ionosphere and that they are frontal in nature. Amorim et al. [2011] evidenced the occurrence of spread- $F$ at the same time that the all-sky images registered MSTIDs over the zenith of CP, and they found that both the peak height and the virtual height ionospheric parameters registered uplifting. Makela et al. [2010] observed interesting airglow OI $630 \mathrm{~nm}$ band structures extending from low-latitude to near-equatorial regions (type MSTID), propagating toward the northwest, during a deep low solar activity period. All these observations show that the presence of MSTIDs, at low latitudes, is a very common feature and can be a source of irregularities causing spread- $F$ signatures on the ionograms.

[17] Both cases presented in this investigation are very interesting examples of an ionospheric structure developing at or above the $F_{2}$-layer. The time evolution of the atypical nighttime spread- $F$ structure reinforces the idea that ionization transport processes related to MSTIDs, propagating at low latitudes, may be a source for generating spread- $F$, satellite trace or $F_{2}$-layer stratification [Abdu et al., 1982b, Amorim et al., 2011; Cabrera et al., 2010; Fagundes et al., 2007]. However, the cases illustrated in this work suggest that MSTIDs, in the initial phase, must have a strong horizontal component, compared to the vertical component, and propagate just above or at the $F_{2}$-layer peak height. In this case, it seems that the MSTIDs were able to construct a situation that caused spread- $F$ formation, via $F$-layer upward and downward movements during MSTIDs events. Amorim et al. [2011], using simultaneous measurements of all-sky images (OI $630.0 \mathrm{~nm}$ ) and ionosonde, at low latitude, showed the presence of spread- $F$ at the same time that dark bands (MSTID) are propagating over the zenith, associated with a rise in the ionospheric $F$-layer. These rises are explained as being due to drifts $E p \times B$ where $E p$ is the polarization electric field inside the MSTID structures.

[18] However, the spread- $F$ was generated above the $F_{2}$-layer peak height, which is very different from the largescale spread- $F$ that is usually generated near the $F$-layer bottom side. Another aspect to be considered is that this phenomenon may be somewhat related to the deep low solar activity period that took place in 2010 .

[19] The occurrence of an atypical spread- $F$ structure at low latitudes is reported. The occurrence of this atypical phenomenon can be subdivided into four stages: 1) A faint structure is seen as a few echoes above the $F_{2}$-layer trace in ionograms; 2) The structure becomes stronger and evolves into spread- $F$ characteristics, but it is still not connected with the $F_{2}$-layer trace; 3 ) The structure merges with the $F_{2}$-layer trace and becomes an atypical spread- $F$; and 4 ) The atypical spread- $F$ disconnects from the $F_{2}$-layer trace and disappears, or it merges with the $F_{2}$-layer trace and disappears. It is 
important to mention that the structure was observed simultaneously by GPS ROT variation although the GPS technique is better to observe larger structures and during moderate-high solar activity, when the total electron content (TEC) is larger.

[20] In this paper, we presented what appears to be another ionogram signature of MSTIDs propagating above or at $F_{2}$-layer peak that generates an extra ionospheric structure just above or at the $F_{2}$-layer, during nighttime, at low latitudes. The observed characteristics of this atypical nighttime spread- $F$ trace structure indicate that some unknown or not well-understood generation mechanisms may be related to MSTIDs and spread- $F$ at low-latitude regions. Furthermore, the structure, on both occasions, is observed first at SJC and after a few minutes at $\mathrm{CP}$, suggesting that the structure propagates toward northeast. However, to determine the structure direction and speed at least three ionosondes closely spaced are needed. The GPS ROT data suggests that this structure is located around the two closely spaced ionosonde stations. Therefore, coordinated observations from multisites and multi-instruments (optical and radio) are relevant and important to understand the features of this kind of structure.

[21] Acknowledgments. Thanks are due to the Brazilian funding agencies FAPESP and CNPq for the partial financial support through grants 2008/05482-5 (FAPESP) and 301469/2009-1 (CNPq).

[22] Robert Lysak thanks the reviewers for their assistance in evaluating this paper.

\section{References}

Aarons, J., M. Mendillo, and R. Yantosca (1997), GPS phase fluctuations in the equatorial region during sunspot minimum, Radio Sci., 32 , 1535-1550, doi:10.1029/97RS00664.

Abalde, J. R., P. R. Fagundes, J. A. Bittencourt, and Y. Sahai (2001), Observations of equatorial $F$ region plasma bubbles using simultaneous OI $777.4 \mathrm{~nm}$ and OI $630.0 \mathrm{~nm}$ imaging: New results, J. Geophys. Res., 106(A12), 30,331-30,336, doi:10.1029/2001JA001115.

Abdu, M. A., and R. T. Medeiros, and J. H. A. Sobral (1982a), Equatorial spread- $F$ instability conditions as determined from ionograms, Geophys. Res. Lett., 9(6), 692-695, doi:10.1029/GL009i006p00692.

Abdu, M. A., I. S. Batista, and I. J. Kantor, and J. H. A. Sobral (1982b), Gravity wave induced ionization layers in the night $F$ region over Cachoeira Paulista $\left(22^{\circ} \mathrm{S}, 45^{\circ} \mathrm{W}\right)$, J. Atmos. Sol. Terr. Phys., 44(9), 759-767, doi:10.1016/0021-9169(82)90004-6.

Abdu, M. A., I. S. Batista, and J. H. A. Sobral (1992), A new aspect of magnetic declination control on equatorial spread- $F$ and $F$-region dynamo, J. Geophys. Res., 97(A10), 14,897-14,904, doi:10.1029/92JA00826.

Amorim, D. C. M., A. A. Pimenta, J. A. Bittencourt, and P. R. Fagundes (2011), Long-term study of medium-scale traveling ionospheric disturbances using O I $630 \mathrm{~nm}$ all-sky imaging and ionosonde over Brazilian low latitudes, J. Geophys. Res., 116, A06312, doi:10.1029/2010JA016090.

Balan, N., and G. J. Bailey (1995), Equatorial plasma fountain and its effects: Possibility of an additional layer, J. Geophys. Res., 100(A11), 21,421-21,432, doi:10.1029/95JA01555.

Balan, N., G. J. Bailey, M. A. Abdu, K. I. Oyama, P. G. Richards, J. MacDougall, and I. S. Batista (1997), Equatorial plasma fountain and its effects over three locations: Evidence for an additional layer, the $F_{3}$ layer, J. Geophys. Res., 102(A2), 2047-2056, doi:10.1029/95JA02639.

Balan, N., I. S. Batista, M. A. Abdu, J. MacDougall, and G. J. Bailey (1998), Physical mechanism and statistics of occurrence of an additional layer in the equatorial ionosphere, J. Geophys. Res., 103(A12), 29,169-29,181, doi:10.1029/98JA02823.

Balan, N., S. V. Thampi, K. Lynn, Y. Otsuka, H. Alleyne, S. Watanabe, M. A. $\mathrm{Abdu}$, and B. G. Fejer (2008), $F_{3}$ layer during penetration electric field, J. Geophys. Res., 113, A00A07, doi:10.1029/2008JA013206.

Batista, I. S., M. A. Abdu, J. MacDougall, and J. R. Souza (2002), Long term trends in the frequency of occurrence of the $F_{3}$ layer over Fortaleza, Brazil, J. Atmos. Sol. Terr. Phys., 64, 1409-1412, doi:10.1016/S13646826(02)00104-9.

Batista, I. S., M. A. Abdu, A. M. da Silva, and J. R. Souza (2003), Ionospheric $F_{3}$ layer: Implications for the IRI Model, Adv. Space Res., 31(3), 607-611, doi:10.1016/S0273-1177(03)00023-1.
Bittencourt, J. A., Y. Sahai, P. R. Fagundes, and H. Takahashi (1997) Simultaneous observations of equatorial $F$ region plasma depletions and thermospheric winds, J. Atmos. Sol. Terr. Phys., 59(9), 1049-1059, doi:10.1016/S1364-6826(96)00071-5.

Cabrera, M. A., M. Pezzopane, E. Zuccheretti, and R. G. Ezquer (2010), Satellite traces, range spread- $F$ occurrence, and gravity wave propagation at the southern anomaly crest, Ann. Geophys., 28(5), 1133-1140, doi:10.5194/angeo-28-1133-2010.

Calvert, W., and R. Cohen (1961), The interpretation and synthesis of certain spread- $F$ configurations appearing on equatorial ionograms, J. Geophys. Res., 66(10), 3125-3140, doi:10.1029/JZ066i010p03125.

Depuev, V. H., and S. A. Pulinets (2001), Intercosmos-19 observations of an additional topside ionization layer: The $F_{3}$ layer, $A d v$. Space Res., 27(6-7), 1289-1292.

Fagundes, P. R., Y. Sahai, J. A. Bittencourt, and H. Takahashi (1995), Relationship between generation of equatorial $F$ region plasma bubbles and thermospheric dynamics, Adv. Space Res., 16(5), 117-120, doi:10.1016/0273-1177(95)00180-M.

Fagundes, P. R., Y. Sahai, I. S. Batista, M. A. Abdu, J. A. Bittencourt, and H. Takahashi (1999), Observations of day-to-day variability in precursor signatures to equatorial $F$ region plasma depletions, Ann. Geophys., 17(8), 1053-1063, doi:10.1007/s00585-999-1053-X.

Fagundes, P. R., V. Klausner, Y. Sahai, V. G. Pillat, F. Becker-Guedes, F. C. P. Bertoni, M. J. A. Bolzan, and J. R. Abalde (2007), Observations of daytime $F_{2}$-layer stratification under the southern crest of the equatorial ionization anomaly region, J. Geophys. Res., 112, A04302, doi:10.1029/ 2006JA011888.

Fagundes, P. R., J. A. Bittencourt, J. R. Abalde, Y. Sahai, M. J. A. Bolzan, V. G. Pillat, and W. L. C. Lima (2009a), $F$ layer postsunset height rise due to electric field prereversal enhancement: 1 . Traveling planetary wave ionospheric disturbance effects, J. Geophys. Res., 114, A12321, doi:10.1029/2009JA014390.

Fagundes, P. R., J. R. Abalde, J. A. Bittencourt, Y. Sahai, R. G. Francisco, V. G. Pillat, and W. L. C. Lima (2009b), $F$ layer postsunset height rise due to electric field prereversal enhancement: 2 . Traveling planetary wave ionospheric disturbances and their role on the generation of equatorial spread F, J. Geophys. Res., 114, A12322, doi:10.1029/2009JA014482.

Fagundes, P. R., V. Klausner, J. A. Bittencourt, Y. Sahai, and J. R. Abalde (2011), Seasonal and solar cycle dependence of $F_{3}$-layer near the southern crest of the equatorial ionospheric anomaly, Adv. Space Res., 43(3), 472-477, doi:10.1016/j.asr.2011.04.003.

Jenkins, B. G., J. Bailey, M. A. Abdu, I. S. Batista, and N. Balan (1997), Observations and model calculations of an additional layer in the topside ionosphere above Fortaleza, Brazil, Ann. Geophys., 15, 753-759, doi:10.1007/s00585-997-0753-3.

Klimenko, M. V., V. V. Klimenko, K. G. Ratovsky, L. P. Goncharenko, Y. Sahai, P. R. Fagundes, R. de Jesus, A. J. de Abreu, and A. M. Vesnin (2011), Numerical modeling of ionospheric effects in the middle- and lowlatitude $F$ region during geomagnetic storm sequence of 9-14 September 2005, Radio Sci., 46, RS0D03, doi:10.1029/2010RS004590.

Lynn, K. J. W., T. J. Harris, and M. Sjarifudin (2000), Stratification of the $F_{2}$ layer observed in Southeast Asia, J. Geophys. Res., 105(A12), 27,147-27,156, doi:10.1029/2000JA900056.

Lynn, K. J. W., Y. Otsuka, and K. Shiokawa (2011), Simultaneous observations at Darwin of equatorial bubbles by ionosonde-based range/time displays and airglow imaging, Geophys. Res. Lett., 38, L23101, doi:10.1029/2011GL049856.

Makela, J. J., E. S. Miller, and E. R. Talaat (2010), Nighttime medium-scale traveling ionospheric disturbances at low geomagnetic latitudes, Geophys. Res. Lett., 37, L24104, doi:10.1029/2010GL045922.

Paul, A., and A. DasGupta (2010), Characteristics of the equatorial ionization anomaly in relation to the day-to-day variability of ionospheric irregularities around the postsunset period, Radio Sci., 45, RS6001, doi:10.1029/2009RS004329.

Paznukhov, V. V., B. W. Reinisch, P. Song, X. Huang, T. W. Bullett, and O. Vellz (2007), Formation of an $F_{3}$ layer in the equatorial ionosphere: A result from strong IMF changes, J. Atmos. Sol. Terr. Phys., 69(10-11), 1292-1304, doi:10.1016/j.jastp.2006.08.019.

Pimenta, A. A., P. R. Fagundes, J. A. Bittencourt, Y. Sahai, and B. Clemesha (2001), Relevant aspects of equatorial plasma bubbles under different solar activity conditions, Adv. Space Res., 27(6-7), 1213-1218, doi:10.1016/ S0273-1177(01)00200-9.

Pimenta, A. A., J. A. Bittencourt, P. R. Fagundes, Y. Sahai, R. A. Buriti, H. Takahashi, and M. J. Taylor (2003), Ionospheric plasma bubble zonal drifts over the tropical region: A study using OI $630 \mathrm{~nm}$ emission all-sky images, J. Atmos. Sol. Terr. Phys., 65(10), 1117-1126, doi:10.1016/ S1364-6826(03)00149-4.

Pimenta, A. A., M. C. Kelley, Y. Sahai, J. A. Bittencourt, and P. R. Fagundes (2008), Thermospheric dark band structures observed in all- 
sky OI $630 \mathrm{~nm}$ emission images over the Brazilian low-latitude sector, $J$. Geophys. Res., 113(A1), A01307, doi:10.1029/2007JA012444.

Pulinets, S. A., V. H. Depuev, A. T. Karpachev, S. M. Radicella, and N. P. Damilkin (2002), Recent advances in topside profile modeling, $A d v$. Space Res., 29(6), 815-823, doi:10.1016/S0273-1177(02)00037-6.

Rama Rao, P. V. S., K. Niranjan, D. S. V. V. D. Prasad, and P. S. Brahmanandam (2005), Features of additional stratification in ionospheric $\mathrm{F}_{2}$ layer observed for half a solar cycle over Indian low latitudes, J. Geophys. Res., 110, A04307, doi:10.1029/2004JA010646.

Sahai, Y., P. R. Fagundes, J. R. Abalde, A. A. Pimenta, J. A. Bittencourt Y. Otsuka, and V. H. Rios (2004), Generation of large-scale equatorial $F$ region plasma depletions during low range spread- $F$ season, Ann. Geophys., 22(1), 15-23, doi:10.5194/angeo-22-15-2004.

Sahai, Y., et al. (2009), Observations of the $F$ region ionospheric irregularities in the South American sector during the October 2003 'Halloween storms,' Ann. Geophys., 27(12), 4463-4477, doi:10.5194/angeo-27-4463-2009.

Sastri, J. H., M. A. Abdu, and I. S. Batista, and J. H. A. Sobral (1997), Onset conditions of equatorial (range) spread- $F$ at Fortaleza, Brazil, during the June solstice, J. Geophys. Res., 102(A11), 24,013-24,021, doi:10.1029/97JA02166.

Sobral, J. H. A., and M. Abdu (1990), A latitudinal gradient in the plasma bubble zonal velocities as observed by scanning $630-\mathrm{nm}$ airglow measurements, J. Geophys. Res., 95(A6), 8253-8257, doi:10.1029/ JA095iA06p08253.

Sobral, J. H. A., M. A. Abdu, H. Takahashi, H. Sawant, C. J. Zamlutti, and G. L. Borba (1999), Solar and geomagnetic activity effects on nocturna zonal velocities of ionospheric plasma depletions, Adv. Space Res. 24(11), 1507-1510, doi:10.1016/S0273-1177(99)00716-4.

Sobral, J. H. A., et al. (2011), Midnight reversal of ionospheric plasma bubble eastward velocity to westward velocity during geomagnetically quiettime: Climatology and its model validation, J. Atmos. Sol. Terr. Phys., 73 , 1520-1528, doi:10.1016/j.jastp.2010.11.031.
Sreeja, V., N. Balan, S. Ravindran, T. K. Pant, R. Sridharan, and G. J. Bailey (2009), Additional stratifications in the equatorial $F$ region at dawn and dusk during geomagnetic storms: Role of electrodynamics, J. Geophys. Res., 114, A08309, doi:10.1029/2009JA014373.

Sreeja, V., S. Ravindran, and T. K. Pant (2010), Features of $F_{3}$ layer occurrence over the equatorial location of Trivandrum, Ann. Geophys., 28 , 1741-1747, doi:10.5194/angeo-28-1741-2010.

Tsunoda, R. T. (2010), On equatorial spread $F$ : Establishing a seeding hypothesis, J. Geophys. Res., 115, A12303, doi:10.1029/2010JA015564.

Uemoto, J., T. Ono, A. Kumamoto, and M. Iizima (2006), Statistical analysis of the ionization ledge in the equatorial ionosphere observed from topside sounder satellites, J. Atmos. Sol. Terr. Phys., 68(12), 1340-1351, doi:10.1016/j.jastp.2006.05.015.

Zain, A. F. M., S. Abdullah, M. J. Homam, F. C. Seman, M. Abdullah, and Y. H. Ho (2008), Observations of the $F_{3}$-layer at equatorial region during 2005 , J. Atmos. Sol. Terr. Phys., 70, 918-925, doi:10.1016/j.jastp.2007.12.002.

Zhao, B., W. Wan, L. Liu, K. Igarashi, K. Yumoto, and B. Ning (2009), Ionospheric response to the geomagnetic storm on 13-17 April 2006 in the west Pacific region, J. Atmos. Sol. Terr. Phys., 71, 88-100, doi:10.1016/j.jastp.2008.09.029.

J. R. Abalde, A. J. de Abreu, P. R. Fagundes, L. P. Moor, M. T. A. H. Muella, and Y. Sahai, Física e Astronomia, Universidade do Vale do Paraíba, Ave. Shishima Hifumi 2911, Sao Jose dos Campos, SP 12244 000, Brazil. (fagundes@univap.br)

M. A. Abdu, D. C. M. Amorim, J. A. Bittencourt, A. A. Pimenta, and J. H. A. Sobral, Instituto Nacional de Pesquisas Espaciais, Ave. dos Astronautas 1758, Sao Jose dos Campos, SP 12242-970, Brazil.

M. Pezzopane, Istituto Nazionale di Geofisica e Vulcanologia, Via di Vigna Murata 605, I-00143, Rome, Italy. 